\title{
REAÇÃO DELIRANTE INDUZIDA. ESTUDO DE EPIDEMIA MENTAL COLETIVA
}

\author{
NELSON PIRES*
}

Há dois anos assistimos, na cidade de Campo-Grande, Estado de Mato Grosso, a uma ocorrência comum no Brasil: um menino analfabeto, obscuro e mentalmente apoucado, a provocar intensa celeuma e romaria de sofredores de tôda a espécie à sua casa em busca de cura ou alívio. Afluiam peregrinos dos Estados de São Paulo, Minas Gerais, e Goiás, por todos os meios de locomoção. O fenômeno social provocou intenso movimento na cidade, onde os hoté:s transbordavam de população doente que os trens incessantemente despejavam. Assistindo de perto aos acontecimentos, surpreendemos alguns aspectos que nos pareceram dignos de negistro. Nada de novo descobrimos e não nos preocupamos com as descrições dos delírios induzidos, clássicas em psiquiatria. Focalizamos o aspecto social por nos parecer mais interessante, visto que o delírio em questão é fiel retrato das condições médico-sociais do interior brasileiro. O fenômeno é sempre curioso, porque é rudimentarmente construído; não obstante, tem conseqüências de grande extensão. Pareceu-nos admirável nesta epidemia, não o santo milagroso, mas a debilidade lógica dos crentes, que atingiu a culminâncias incríveis. O título dêste trabalho — reação induzida - deve-se a uma advertência de Kurt Schneider (Abnorme Erlabnisreaktionen), segundo a qual não existe loucura induzida e, sim, transmissão de "conteúdos psíquicos anormais" de um doente a outro indivíduo. Induz-se apenas a reação ou o conteúdo temático da psicose ou do delírio.

Trata-se de uma família composta de um casal e cinco filhos. $O$ pai é fervoroso crente, às vezes alucinado e portador de idéias místicas supervalentes que, freqüentemente, atingem a condição delirante: é o indutor do episódio que se vai passar. No recesso da família, a reação mística era diária e intensamente vivida pela influência patriarcal dêsse chefe. Ao levantar, ao almôço e jantar, as orações em comum estabeleciam a continuidade do clima religioso; ao deitar, a reza em voz alta, puxada pelo chefe, era o último acontecimento diário. Percebe-se

Trabalho apresentado à Secção de Neuro-Psiquiatria da Associação Paulista de Medicina em 5 janeiro 1946.

* Docente-livre de Psiquiatria Faculdade Fluminense de Medicina. Capitão-médico do Exército. Psiquiatra do Hospital Militar da Bahia. 
até onde ia a sugestão religiosa, pois uma filha de cinco anos sonhava repetidamente com anjos e santos. Os filhos freqüentemente conversavam sobbre temas de religião.

Nas vésperas do episódio prínceps, o filho mais velho, como tantas vezes anteriormente, sonhara que vira Deus no oéu, lendo, em imenso livro, a explicação da causa do conflito mundial (guerra de 1939-45) e o nome das pessoas que iriam para o inferno e para o céu. $O$ pai explicou-lhe que o imenso livro era o Livro do Destino, que existe no céu e é escriturado sob o critério das boas e más ações de cada um. Sôbre a guerra fêz, como já o fizera várias vezes, grande prédica: "Hitler, autoritário e escravizador; a guerra vem da má vontade entre os homens, que não têm amor ao próximo; tudo é vaidade e futilidade; só se vê a procura dos gozos da Terra; os homens esquecem de Deus; as batalhas são assassinatos coletivos; falta ao mundo a religião que tempera as diferenças mediante a tolerância e a ajuda recíproca".

No dia imediato, o futuro santo sonhou que via Nossa Senhora a falar-lhe. Um santo achegou-se e fêz-lhe cócegas, a ponto de acordá-lo em risos. Os dois irmãos confrontaram seus sonhos e inquiriram-se reciprocamente qual seria o mais santo: o que via Deus ou o que vira Nossa Senhora. Parecia vencedor o mais velho, se bem nenhum dêles quisesse a vitória para si, em ostensivo respeito ao outro. Conversou sôbre o sonho também com o pai. Já figurara nas conversas a necessidade que tantos sofredores tinham de serem curados da alma e do corpo. O menino fixara esta última - a cura do corpo - talvez nor não entender a outra. A seguir, em sonhos sucessivos, aparece-lhe a visão, dizendo que the daria forças para curar os homens.

Conta o pai que, pôsto ao par desta determinação, a ela se opôs, pois que era proibido. Este relato é feito, contudo, na delegracia de polícia, em circunstâncias, portanto, que inautenticam a sinceridade de tal afirmação, pois era necessário eximir-se da culpa. Como se repetissem os sonhos, o menino declarara: "Se não me deixarem curar, ficarei louco". Adianta o pai que não desejara que o menino curasse ninguém e que chegou a impedí-lo. Mas um dia avistaram N., antigo alcoolista, embriagado no momento e que, nessas condições, era costumeiro em fazer distúrbios. O pai inquire ao filho: "Podes curar o N.? Aí está um benefício! Reza a Nossa Senhora para que o cure". O menino assentiu. Alguns dias depois, viram $\mathrm{N}$. ordeiro e em estado normal. Isto pareceu ao pai um fato memorável, comentando-o com os 'vizinhos.

Um domingo, pouco tempo após êsse fato, o pai recebeu a visita de um amigo casado, que deixara a espôsa em casa. Interrogando o amigo a respeito da espôsa, soube que ficara em casa por doença, pois "ela estava desenganada por dois médicos, por estar com asma". As crises, nessa moca, eram algo prolongadas, de dois a cinco dias. O pai chamou A. C. (que, aliás, foi sempre seu preferido) e contou-lhe o fato, pedindo que rezassem todos pelo doente. Ao cabo de dois dias recebeu a notícia que ela estava boa. Julgaram-na definitivamente curada da asma, só por haver cedido o acesso. Ao que parece, foram utilizados remédios. Esta notícia da cura foi recebida já como uma consagração. $O$ pai contou-a a todos, contou-a o agradecido marido da doente, e tôda a vizinhança comentou-a.

Afluíram numerosos consulentes e já então não foi mais possível saber qual o terceiro milagre. Aos poucos, as notícias dos milagres percorreram a cidade. O menino atendia aos que o procuravam, rezava e abençoava. Poucas vezes mantinha conversas com os crentes, tarefa que o convicto pai assumia conscienciosamente, inoculando fé em cada doente. Apareceram as primeiras dádivas de dinheiro que, em meio a negáças do pai, eram afinal aceitas, ou eram depositadas sob toalhas, pratos, dentro de vasos de flôres ou plantas, sob jarras, etc.

Como a concentração de doentes os mais diversos ameaçasse a saúde pública, interveio o Juiz, mantendo pai e filho sob custódia e tentando processá-los. Mas, 
não havendo Instituto de Menores, Patronato ou Juizado próprio para custódia, foram recolhidos ao prédio da cadeia pública, em regime especial, semilivres. Daii retirou-os habeas corpus impetrado por um cidadão qualquer, adepto do santo. $\mathrm{O}$ prestígio dêste crescera muito. $\mathrm{Na}$ cadeia, conhecera um outro detento, êste "profeta", um delirante que fôra recluso profilàticamente para pôr fim a uma seita na qual figurava a água ingerida ou usada em banhos como milagrosa. $\mathrm{O}$ profeta reunira em tôrno de sua cabana isolada no mato um verdadeiro acampamento de agonizantes, tuberculosos, morféticos, paralíticos, caquéticos de muitas doenças e loucos em número estimado em mais de mil pela autoridade policial de Campo-Grande.

Nosso observado aprendeu com o "colega" a utilidade da água milagrosa. Retornando ao lar, passou a empregá-la. Como a afluência aumentara extraordinàriamente (o repórter do jornal local estampou que orçava em mais de 900 consulentes diários), o menino santo passou a adotar novo sistema de consultas: o cliente deveria trazer uma garrafa, que era entregue ao pai; êste, que montava guarda ao quarto onde o menino permanecia fechado e invisível, enchia dágua a garrafa e passava-a às mãos do santo, o qual, através da porta do quarto, benzia a água e dizia palavras proféticas: “Tem fé, bebe esta água que, se fôr da vontade de Deus, ela vai te curar". Outras vezes respondia que era provável que o doente não se curasse (isto ocorria com mais freqüência na fase em que atendia pessoalmente aos doentes e recebia impressão direta dêles).

A intervenção policial decretada pelo Juiz abalara a tranquíilidade do lar. Os donativos eram agora recusados de frente, mas aceitos se deixados como espórtulas nas gavetas. Todavia, o chefe não mais sossegara, desde que vira tôda a família detida para depor: resolveu sair e rumar para Araçatuba, em São Paulo, onde instalaram-se em grande e confortável casa, um quse-sanatório, segundo os informantes. A polícia, porém, agiu com mais desenvoltura, compelindo a família a deixar o Estado, regressando todos, depois de dois ou três meses de milagres, a Campo-Grande. Mas os ventos continuaram desfavoráveis; as vicissitudes, que culminaram com a total alteração dos hábitos de vida, com a cadeia, com a mudança e ulterior regresso para a cidade perigosa onde se dera a prisão, tiraram à família tôda a veleidade de prosseguir na luta, ainda que santificada. Tudo, ràpidamente, voltou à normalidade. O pai explicava que o filho deixara de estar em contacto com Nossa Senhora, porque perdera a fôrça milagreira devido à exaustão física da intensa vida anterior. Os crentes, ùltimamente pouco satisfeitos porque o menino atendia, mas invisìvelmente, arrefeceram definitivamente o entusiasmo. $\mathrm{O}$ santo tornou-se um banal foot-baller de rua. $\mathrm{O}$ pai voltou às hortaliças, guardando intactas as reservas místicas e a estenia das convicções. Amealhara alguns milhares de cruzeiros desde que, das prédicas sinceras e das curas inicialmente de boa fé, evoluíra e corrompera-se, industrializando a água e os milagres do filho.

Exame do progenitor do "menino-santo": F. L. C., com 43 anos de idade, casado, português. Biótipo atlético, de pequena estatura. Hipertricose discreta. Aó exame somático, nada há digno de menção. Apresenta-se respeitoso, conversando com facilidade, algo cauteloso e bem atento (o primeiro exame é feito na delegacia). As funções psíquicas simples estão íntegras. Logo de início ataca os temas místicos com profusão de idéias doutrinárias de várias ordens: esotéricas, bíblicas, católicas, espíritas. Há um sistema compacto sôbre temas de amor ao próximo, salvação das almas, conformismo grato ao que Deus the proporcionou. Profunda convicção na assistência divina direta. Percebe-se que sua vida decorreu sempre atenta aos preceitos religiosos e sob êles foi orientada, sofrendo influência pronunciada. Conta que, quando jovem, recusou casamentos ricos porque as moças "não eram piedosas, ou porque eram fúteis, pintavam-se ou criticavam religião". Não bebe e não fuma "por serem vícios". Raramente vai a cinema. Nunca usou gravata, brilhantina, nem jóias, por motivos religiosos. 
Evita vestir terno novo "para não ofender os que não têm facilidade de fazer o mesmo". Diàriamente reza, cam tôda a família, ao levantar, antes e depois das refeições, antes de deitar. Lê livros de esoterismo, referentes à maçonaria e ao catolicismo, os Testamentos novo e antigo e algo sôbre espiritismo, organizando sincretismo de pouca complexidade mas com estrutura mais ou menos sistematizada. No lar, realiza a figura do velho patriarca, severo nos costumes, amoroso dos seus, mas fanático na religião.

Ativo desde as primeiras horas da manhã, trabalha na venda de legumes. Sempre teve feitio sério de trabalhador, sempre foi religioso e conta com alucinações no passado: duma feita, viu, à noite, quando numa esquina se encontrava isolado, um velho seu conhecido, falecido havia tempos. Aproximou-se sem mêdo para conversar sôbre a outra vida, mas o velho obtemperou-1he: "Não mexa com quem está quieto". Algo decepcionado, aos poucos afastou-se e o velho desapareceu. Oito dias mais tarde, voltou a ter uma visão que já vislumbrara vagamente algumas vezes antes e que lhe despertara curiosidade: uma procissão, em que havia muitas luzes. Interpretou como "procissão das almas". Resolveu tirar isso a limpo e aproximou-se dela. A procissão saia de uma igreja, rumando para outra próxima. Esta cena foi vista outras vezes, parecendo tratar-se de sonho intensamente visualizado, sofrendo, depois, a influência de "ilusões da memória". Conta, todavia, que insistiu com outra pessoa com quem se encontrava na ocasião, a qual "quis ver", mas sem conseguí-lo totalmente, sem a intensa visualização.

Durante o exame, invoca Deus e interpreta misticamente tôda nonada que ocorre. Tôda sua atividade mental se desenrola sob o signo das idéias religiosas: "trabalha e ganha, graças a Deus, o bastante para o sustento de todos; tem saúde, porque Deus o ajuda; vivem todos na conformidade da vontade de Deus". Fala amiúde na "busca da verdade", no desentendimento dos homens, na má vontade que reina no mundo, mas isso com ingenuidade repassada e certo de que a religiosidade concertaria tudo. Cultiva amizades, sem nunca encontrar motivos para disputas fanáticas, simplesmente se retirando quando o clima psicológico é de futilidade e indiferença. Só se preocupa com o que diz respeito à assistência religiosa e material aos seus. Domina francamente o ambiente familiar com essas idéias místicas. Transforma incidentes sem importância em oportunidades para prédicas, citando a Bíblia, história sagrada e Evangelho, sempre que algo fora da rotina ocorre consigo ou com os seus.

Quando o observador interroga o filho, êle não consegue evitar intervir, ajudando-o, respondendo por êle, esclarecendo-lhe o sentido das nossas perguntas, mas êsses esclarecimentos são feitos de tal modo que já estão insinuadas as respostas. Está certo que milagrosa assistência divina protege o filho. A intervenção da polícia, não a discute nas primeiras entrevistas na delegacia e pretende que seu filho não dera consultas médicas pagas mas apenas fazia milagres com a graça de Deus. Defendia-se da pecha de estar curando como médico, pois tudo era do âmbito religioso.

Viemos a saber que, depois dos grandes lucros, melhorara o standard de vida, aumentando o vulto de suas despèsas. Pérguntamos-lhe como poderia saldar pontualmente tais compromissos, visto que deixara de trabalhar dias inteiros para atender aos consulentes. Respondeu-nos que "Deus nos ajuda eu não sei como, mas Deus sabe como faz" e sorriu misteriosamente diante da nossa surprêsa. Informou que "o dinheiro aparece, Deus faz com que êle não falte". Acabamos por compreender que a tal oculta ajuda divina eram os donativos que apareciam em lugares mais ou menos escondidos. Não nos pareceu que sura convicção fôsse fraudulenta ao invocar o divino auxílio.

O filho mais velho apareceu-nos duas vezes e pudemos observar a desvelada solicitude com que assistia ao irmão, que reputava um santo perseguido. Como The notássemos também profunda anemia, aconselhamos o uso de medicamento 
qualquer e esperamos sua reação. Respondeu-nos que estava fazendo uso da água milagrosa do irmão já havia tempos. Retrucamos que não se notavam os esperados resultados. Tornou-se mais sério, encolheu os ombros e foi tratar do irmão, dispensando nossos cuidados. Estava absolutamente convencido que o outro era mesmo assistido por Deus e nós uns infiéis.

Os demais irmãos eram excessivamente jovens para permitirem bons resultados em exame psicológico feito em delegacia. A măe do menino "santo" era de côr parda, permanentemente cabisbaixa, também admitindo a santidade do filho sem discutí-la e sem preocupar-se com os fenômenos místicos. Sem sombra de cultura, analfabeta, mal cuidada e escrava da família grande, cuidava todo tempo apenas dos afazeres domésticos; aceitava tudo com plena passividade, denotando velha subjugação.

Exame do "menino-santo": A. C., pardo, com 13 anos de idade, anal fabeto, longilíneo, anemiado profundamente. Não há maior interêsse no exame somático. Apresenta-se muito reservado, com poucos movimentos; senta-se na cadeira e aí fica com as mãos cruzadas sôbre o peito, falando lentamente. $O$ exame intelectual revela inteligência muito pouco desenvolvida. Furta-se aos testes como cousa inútil, que não são de seu agrado. Propostas questões de contas e de argúcia relativas, falha nelas. Não se determinou a idade mental, dada a atitude assumida. E um “santo" que não quer ser perturbado.

A título de ensaio experimental, chamamos uma irmã de caridade para conversar com o observado. Frente a ela, intimida-se, retrai-se, tornando-se mudo e como quem não entende o que se está passando. Diz que vê Nossa Senhora diàriamente, que o assiste trabalhar. Ela entra às 8 horas da manhã, quando êle inicia as consultas, e fica no quarto de cima, só se retirando quando o trabalho acaba, à noite. Aos sábados e domingos, êle não trabalha, ela não vem também. Contradiz-se quando cerramos o interrogatório sôbre se a visão é real ou em sonhos. Sempre que em dificuldades, olha para seu pai à cata de proteção. Recorre, de contínuo. se embaraçado, ao argumento de ver Nossa Senhora, em evidente atitude de vencer as dificuldades, antepondo a santa como escudo.

Procuramos, depois de examinar o menino em condições normais, reexaminá-lo em plena ação. Provocamos demonstração prática de sua capacidade de vidente, sempre alegada. Dizia êle poder, fechando os olhos, assistir a qualquer fato que se passasse no mundo, naquele instante. Preparamos a encenação estando presentes cêrca de dez pessoas. Pedimos que visitasse a aldeia natal de seu pai e a descrevesse. Fechando os olhos, lentamente começou a narrar: "Havia uma subida, muita erva, muita pedra, umas pessoas trabalhando, todos satisfeitos". Sôbre o que se passava no momento na linha de frente, revelou: "Muitos homens, muitos tiros, canhões e muita gente morta e ferida". Ajunta que Hitler vai perder a guerra; que esta guerra é devida à vaidade dos homens, falta de amor e à sua mania de mandar (de Hitler). Pedimos, enfim, que nos descrevesse o Rio de Janeiro, onde só estivera na extrema infância. Referiu "que via um bonde pendurado no ar". Inquirimos dos trilhos dêsse bonde e êle, com hesitaçōes, passou a dizer que via os trilhos de ferra, em número de dois. "O bonde era aberto, tinha muitas rodas e andava em cima dos morros". O pai, assistindo a tudo isso, mostrava-se inteiramente satisfeito e convencido do milagre. Esclarecemos ao pai que o bonde, o Pão de Açúcar não tinha rodas nem andava sôbre trilhos; que o que o menino contara do Rio, ou era apenas o que haviam descrito ou o que havia visto nas fotografias correntes em tôda a parte, mas que não pudera evitar o êrro das rodas, dos trilhos e do bonde aberto. Insistimos que se tratava de uma mistificação voluntária e grosseira. $O$ pai nem se dignou discutir. Afâstou o assunto "pois que não éramos crentes". Os dados banalíssimos sôbre sua aldeia natal chegavam-lhe de sobra para admitir "que era mesmo tal e qual sua terra natal". Não lhe ocorria que êle próprio descrevera sua aldeia 
dezenas de vezes, em casa. Quanto à guerra, as imagens referidas eram também de uma banalidade insuperável.

Nessa mesma sessão, ficou de novo patenteada, de maneira flagrante, a atitude induzida. Uma irmã de caridade assistia a essas demonstrações e, quando ouviu referência do menino às visões de Nossa Senhora, perguntou-lhe, hostilmente, como ela estava vestida. Respondeu-lhe o menino que com saia de uma côr e blusa de outra. Sob pressão da irmã, informou côres que não figuram realmente nas estampas da Virgem nem são tradicionais no culto religioso. A irmã criticou àsperamente o êrro, negou que houvesse visão de alguma cousa e corrigin as côres. Minutos depois, entrou na sala outra irmã e perguntou também qual a côr das vestes de Nossa Senhora. O menino fechrou os olhos, como que caiu em transe e repetiu as côres que a primeira irmã havia ensinado. $O$ pai não se mostrava preocupado com a má qualidade das burlas do menino. Estava sorridente e convencido, supondo que todos, por sua vez, não mais duvidariam das sobrenaturais qualidades do filho.

\section{DEDUÇOES PSICOPATOLOGICAS}

$\mathrm{O}$ exame verifica, sem maiores dificuldades, que o menino, na fase atual, é simulador, e o pai, um fanático. Mas do exame procedido na delegaciia e na cadeia pública não se poderá deduzir que a atividade "milagrosa" decorrera pura e simplesmente da simulação. Ao menos, isso não fôra sempre assim.

$\mathrm{O}$ chefe, despejando incitações místicas incessantes, propagou a tôda a família petrificadas convicções expressas nos sonhos de vários filhos, nos propósitos e nas preocupações monocórdias com a religião. $\mathrm{O}$ início dos milagres é assinalado por episódio que a ninguém ocorreria taxar de milagre: um aloolista excitado que, sem a bebida, perde a excitabilidade anormal. Apenas por vê-lo ordeiro, já se fala em sobrenatural, sem maiores cogitações. $O$ segundo milagre é do mesmo valor psicopatológico: uma antiga sofredora de asma, ao ter um dos habituais acessos, está desenganada; possivelmente tal afirmação nasceu depois da cura do acesso, para realçar o valor dela. A acalmia dos paroxismos dispneicos já é situlada como cura. O próprio modo de adquirir as propriedades milagrosas traça bem a mentalidade infantil: ouvira o pai falar dos males da alma e do corpo. Não entendendo como se há de salvar a alma, anuncia-se-lhe Nossa Senhora com a outorga da faculdade de curar o corpo. Tal aptidão era exercida pela oração e por palavras proféticas análogas às das citações sacras de tôda a origem, freqüentemente externadas pelo pai. Mas depois de recolhido à cadeia, conheceu um "profeta" que curava com a água. Retornando ao lar, passou também a utilizá-la. Tal conduta mostra o velho hábito de reproduzir o que via e ouvia, sem nada criar de seu, isto é, numa palavra, o seu papel de "induzido". Numa terceira fase, o santo não aparece mais aos fiéis, mas nessa altura o velho pai já industrializara ns milagnes e ambos agiam de má fé ; visavam apenas atender ao maior número possível de crentes. Também observamos outra curiosidade: quando o examinamos, manifestamos surprêsa pelo fato de julgar todos 
os casos curáveis; soubemos que, de então em diante, passara a desenganar seus doentes com maior freqüência.

Pontos de reparo interessantes parecem-nos os seguintes:

$a$ - A influência da catatimia no delírio do pai é absolutamente maciça. Poucas vezes se verá fato tão típico como os que ocorrem a cada passo com êsse fanático: o dinheiro que aparece em vários lugares é dádiva de Deus; o homem que se compartava bem quando não estava alcoolizado era "um louco curado"; o acesso de asma episódico que declinou como tantos outros indicava a cura da asma; as ervas, as pedras, a subida do morro, eram a fiel reprodução de sua terra natal. O delírio do pai é, por inteiro, o dilírio catatímico (katathyme Wahnbildung) de H. W. Mayer. Notar como está inibido ou paralisado o julgamento crítico. Disso trata Bleuler a propósito da "Affektivität, Suggestibilität und Paranoia", observando que, quando está em marcha a catatimia, nem sequer ocorre argumentos que lhe poderiam opor entraves. Não há apenas uma corrente de idéias que supera as outras; há, mesmo, inibição das correntes contrárias; há uma facilitação das agonistas e, às vezes, nem aparecem as antagonista .

$b-\mathrm{O}$ início do episódio por sonhos sucessivos (em autêntica realização de desejos induzidos), já tinha sido assinalado por Kraepelin.

$c$ - A atribuição a Nossa Senhora do hábito de week-end. O observado só adotou a semana inglêsa muito tempo depois de haver-se tornado milagroso; precisando de descanso, infantilmente. condicionou a aparição da Virgem ao horário de seu trabalho.

$d$ - A eliminação dos acontecimentos da vida real, sempre que havia hostilidade. Então, ou o menino "não entendia" o que ouvia, ou entrava em estado de pseudo-alheamento. Isso deu-se na sessão, quando interveio a irmã de caridade.

$O$ delírio tem aquela nota típica que os alemães chamam, com propriedade, "spieglerisch". Trata-se duma produção com traços de infantilismo e de divertimento. Não é preciso dizer que tôdas as suas atividades mentais correlatas com o delírio estão subordinadas ao pai, que lhes dá estímulo, coordenação e material. $\mathrm{O}$ embricamento do delírio místico com a simulação fêz-se claro quando estava detido na cadeia. O fato atesta a verdade, já clàssificamente estabelecida, das psicoses de prisão; o cunho desiderativo do delírio.

Observações esparsas sôbre os crentes - Conseguimos entrevistar um ou outro crente. Um dêles, que se esmerava em dar assistência ao menino na prisão, dizia-se curado de dôres gástricas, sobrevindas com a ingestão de bebidas alcoólicas ou provocadas pelos alimentos fritos. Fôra-lhe diagnostícada uma úlcera péptica, confirmada radiològicamente. Propuzeram-lhe a gastrectomia e, no entretempo, a dieta adequada. Relutara em aceder à intervenção, por mêdo. Estava nesse impasse, 
quando soube dos milagres do menino. Bebera da água santa e curarase. Interrogando-o, soubemos que, agora, podia alimentar-se com qualquer espécie de fritura e de bebida. Comemorara, mesmo, a cura, com libações alcoólicas e um banquete. Violando o "primo non nocere", com intuito de revisar a cura possível, explicamos-lhe que talvez não estivesse realmente curado. Explicamos-lhe mais que, se nada sentia agora, isso podia decorrer de puro fenômeno banal de sugestão e que, afinal, șabia-se hoje que a úlcera gástrica advém principalmente em nervosos, lábeis emotivos perfeitamente acessíveis à sugestão e que daí, até estivesse mesmo curado orgânicamente. Seria mais convincente a comprovação radiológica, sempre interessante do ponto de vista médico. $O$ doente negaciou e esquivou-se "a gastar mais centenas de cruzeiros, pois nada sentia". Notar que se tratava de homem rico.

Constavam curas milagrosas de paralíticos. Procurâmo-los; não havia paralíticos e nem mesmo outros doentes nos lugares dados como pouso residencial dêles. Ainda uma vez os "consta" impessoais, irresponsáveis, impregnavam a atmosfera, propiciando o futuro milagre; o clima dado por êsses milagres inexistentes não tinha autor definido. Provàvelmente, tratava-se daquela contribuição inconsciente que cada crente concede, seja veiculando a anônima versão, seja avultando o fenômeno visto, ouvido ou sabido, seja vivendo-o a seu modo e relatando-o. já agora irreconhecível, deformado pela catatimia. Há uma necessidade de crença, como há a necessidade de delírio (Wahnbedürfnis, de Kraepelin), em certos estados de humor patológicos. A necessidade de crença, como a outra de Kraepelin. alimenta-se com qualquer fato que tenha aparência de verdade. Aqui bastava a longínqua verossimilhança milagrosa. Não se exige certificado de fora, quando internamente se está sob a "onipotência das idéias" (Klimacht der Gedanken, de Freud), ou seja, a realidade subjetiva.

Fomos chamados várias vezes a atender doentes que não curaram com a água milagrosa. Quase sempre, a atitude dos doentes não curados era de reserva absoluta, evitando dizer que nada haviam ganho com a beberagem. Quando chegavam a tal contingência, faziam as revelações ao médico em voz baixa e na intimidade. Possìvelmente, temiam levantar contra si suspeitas de incredulidade ou qualquer modalidade de luta que implicasse em isolamento moral.

Alguns dados sôbre as condições mesológicas - A população da cidade orça em 30.000 habitantes. Há um pôsto de saúde, um hospital com clínica em parte gratuita e em parte paga ; os médicos que lá clinicam fazem medicina cara. Do ponto de vista da assistência social, a população é semidesvalida. O nível médio mental muito baixo, o desamparo assistencial, a religiosidade inculta vigente no interior do Bra- 
sil, onde qualquer acontecimento é transformado fàcilmente em sentido fantástico - os lobisomens, as almas penadas, etc. - explicam clàssicamente os fenômenos da fanatização coletiva. Não queremos falar na psicologia das massas, sempre invocada.

Os jornais da localidade, sempre às voltas com a falta de assunto e de circulação, noticiavam extensamente os pretensos milagres e dados sensacionalistas sôbre a biografia do santo e sua família. Interpelado o redator do jornal, respondeu-nos que sabia tratar-se de fraude e ingenuidade misturadas, mas que tal noticiário aumentava muito a venda do jornal. Os chauffeurs que transportavam os peregrinos da estação da estrada-de-ferro aos hotéis e dêstes ao longínquo bairro, organizavam como podiam a propaganda, que thes trazia, também, frutos nas escursões, cada vez mais caras, ao antro do menino famoso. Os hoteleiros, surpreendidos com o inesperado acréscimo de hóspedes e, já, como os chauffeurs, um tanto convencidos da realidade sobrenatural das curas, não tinham senão que veicular mais caprichadamente o murmúrio dos milagres que lhes favorecia diretamente o negócio de hospedar peregrinos.

Não vimos que a igreja interviesse oficialmente. $O$ episódio da irmã fôra por nós preparado, no intuito de verificar como se comportariam as religiosas e como a elas reagiria o suposto santo. $O$ conflito de crenças interessou-nos do ponto de vista psicológico. Talvez a igreja estivesse esperando que o movimento místico se tornasse avassalador, para pronunciar-se. Tampouco apareceu a fiscalização ao exercício ilegal da medicina. $\mathrm{O}$ pốsto.de saúde pública estadual ali funcionando, determinou-se a não intervir; possìvelmente, adotou a atitude que é o símile nacional do "gentleman's agreement" - não intervir para não levantar inquietante luta, isto é, para não se incomodar sèriamente. Isto porque, a esta altura, já a freqüência comportava pessoas de certa projeção social e até com instrução superior. Tanto vale a catatimia...

Para rematar, respigaremos de novo o desfêcho, que retrata bem as condições sociais de nosso hinterland, no que tange à assistência psiquiátrico-social: o Juiz, aliás inteligente e culto, deteve o menor e seu pai para pôr fim à calamidade que consistia em aglomerar na cidade quanto doente incurável e contagiante houvesse no eixo ferroviário que servia aquela povoação (o obituário urbano triplicara). Apesar do habeas corpus, o processo prosseguiu. A extinção do episódio mental deve-se à renúncia da família do santo em continuar a luta, já atribulada pelo Juiz e pela polícia. Não obtendo tranqüilidade também em Araçatuba, desfez-se como pôde do ônus de curar contra a vontade de tantas autoridades...

Hospital Militar, Salzador - Estado da Bahia. 